\title{
Pemberdayaan Suku Polahi Melalui Konsep Agroforestri untuk Menjaga Kelestarian Suaka Margasatwa Nantu
}

\author{
Muhammad Rum Laindi ${ }^{*}$, Fidyatul Husna Wartabone ${ }^{2}$, Ikrima Staddal ${ }^{1}$ \\ ${ }^{1}$ Program Studi Mesin dan Peralatan Pertanian Pertanian \\ ${ }^{2}$ Program Studi Teknik Informatika \\ Politeknik Gorontalo \\ Jl. Muchlis Rahim Bone Bolango 96112 Gorontalo \\ *E-mail : rumhezekiah@gmail.com \\ DOI: https://doi.org/10.21107/pangabdhi.v7i2.11486 \\ Naskah diterima 28 Mei 2021, Revisi 27 Agustus 2021, Terbit 29 Oktober 2021
}

\begin{abstract}
Abstrak
Suku Polahi termasuk salah satu suku terasing di Indonesia dan memiliki kultur kebudayaan yang masih melekat kuat. Sampai saat ini aktifitas Suku Polahi dengan masyarakat luar masih sangat terbatas. Kontak langsung dengan Suku Polahi hanya dilakukan oleh masyarakat yang mencari rotan ke dalam hutan dan juga beberapa masyarakat dari Desa terdekat. Suku Polahi tinggal disepanjang hutan Boliyohuto di dalam kawasan konservasi Suaka Margasatwa Nantu. Suku Polahi untuk bertahan hidup menebang pohon untuk ditanami tanaman jagung dan juga dijual kepada pencari kayu di hutan. Kegiatan ini bertujuan untuk memberikan pemaham kepada Suku Polahi tentang status Suaka Margasatwa Nantu yang harus dijaga, memberikan pemahaman tentang pelarangan penebangan pohon dan memberikan pelatihan cara menanam secara agroforestri. Hasil dari kegiatan ini memperlihatkan bahwa pengetahuan Suku Polahi tentang Agroforestri semakin bertambah, dimulai dengan cara pemilihan bibit pohon yang baik, cara penenaman denga metode konservasi dan cara untuk merawat serta menjaga bibit yang telah ditanam. Selain itu Suku Polahi telah memahami tentang status Suaka Margasatwa Nantu yang harus dijaga dan dilindungi. Kegiatan ini diharapkan bahwa Suku Polahi yang telah mengikuti kegiatan ini bisa mengajarkan pada Suku Polahi lainnya sehingga kelestarian Suaka Margasatwa Nantu dapat dijaga.
\end{abstract}

Kata Kunci : Suku Polahi, agroforestri, suaka margasatwa, konservasi, pelatihan

\section{PENDAHULUAN}

Polahi adalah para pencari rotan dan damar pada masa kolonialisme yang kemudian memilih dan menetap di hutan dan kemudian tidak lagi kembali ke kampung halaman mereka sampai setelah Gorontalo merdeka pada tahun 1942. Polahi dalam bahasa Gorontalo memiliki arti "pelarian". Masyarakat Gorontalo yang ketika itu melarikan diri dan masuk ke dalam hutan terjadi pada masa Raja Eyato dan Raja Biya (1677-1679) serta pada masa dua tokoh masyarakat Sumalata yaitu Olabu dan Tamuu sekitar tahun 1899 (Pomalingo, 2015).

Suku Polahi termasuk salah satu suku terasing di Indonesia dan memiliki kultur kebudayaan yang masih melekat kuat. Kebudayaan Suku Polahi dalam sistem perkawinan menerapkan perkawinan sedarah atau incest yang kemudian menjadi polemik yang sampai sekarang belum terselesaikan. Sampai saat ini aktifitas Suku Polahi dengan masyarakat luar masih sangat terbatas. Kontak langsung dengan Suku Polahi hanya dilakukan oleh masyarakat yang mencari rotan ke dalam hutan dan juga beberapa masyarakat dari Desa terdekat. Beberapa Suku Polahi ada yang telah terbuka dan berinteraksi dengan masyarakat bahkan sudah menikah dengan warga desa tetapi hal ini tetap menjadi kendala untuk mendapatkan informasi tentang kehidupan Suku Polahi dikarenakan sikap tertutup dan ketakutan mereka dengan orang baru.

Pada pertemuan pertama dengan Suku Polahi dilakukan bersama dengan pihak dari Balai Konservasi Sumberdaya Alam yang dibawahi Kementerian Lingkungan Hidup dan Kehutanan Republik Indonesia, hal ini dikarenakan Suku Polahi berada dalam kawasan Suaka Margasatwa Nantu yang merupakan kawasan vital konservasi. Pertemuan pertama bertujuan melihat aktifitas sehari-hari dari Suku Polahi terutama cara mereka dalam bercocok tanam. Suku Polahi yang menjadi mitra kegiatan ini melakukan aktivitas bercocok tanam dengan cara membuka lahan secara manual pada lahan dengan kemiringan $>25 \%$, setelah 
lahan dibuka selanjutnya dibiarkan. Pembiaran lahan secara terbuka ini bisa berlangsung sampai 3 bulan sehingga hal ini bisa meningkatkan tanah lebih mudah tererosi (Gambar 2).

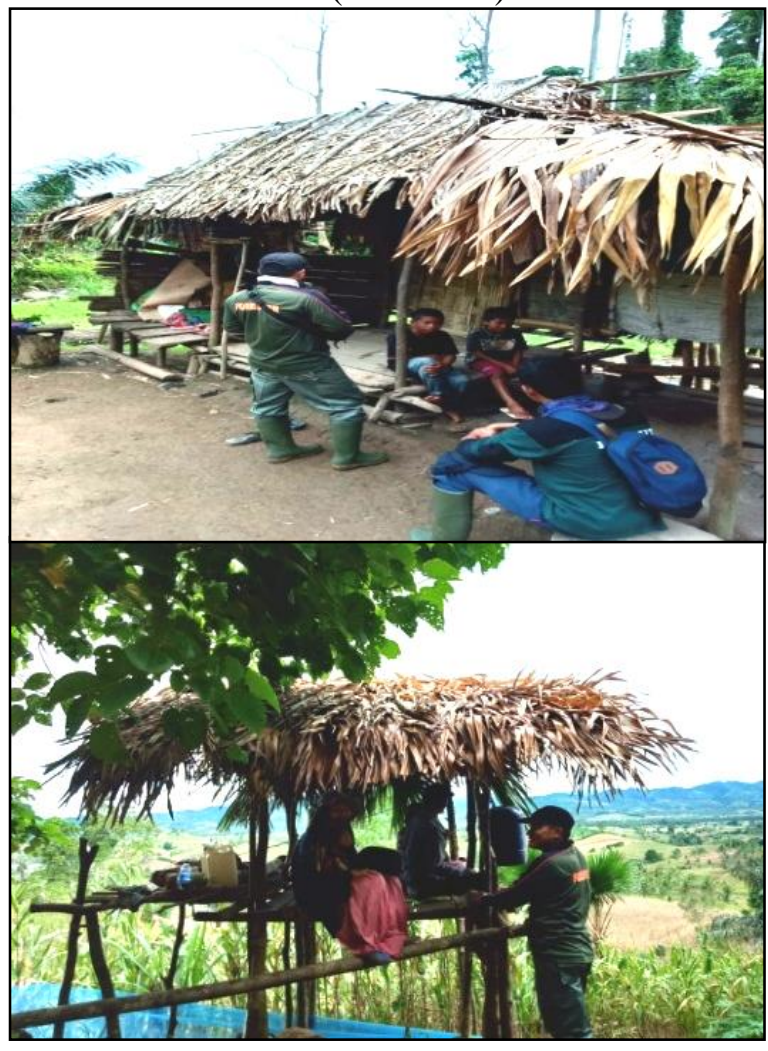

Gambar 1. Pertemuan dengan Anggota Suku Polahi

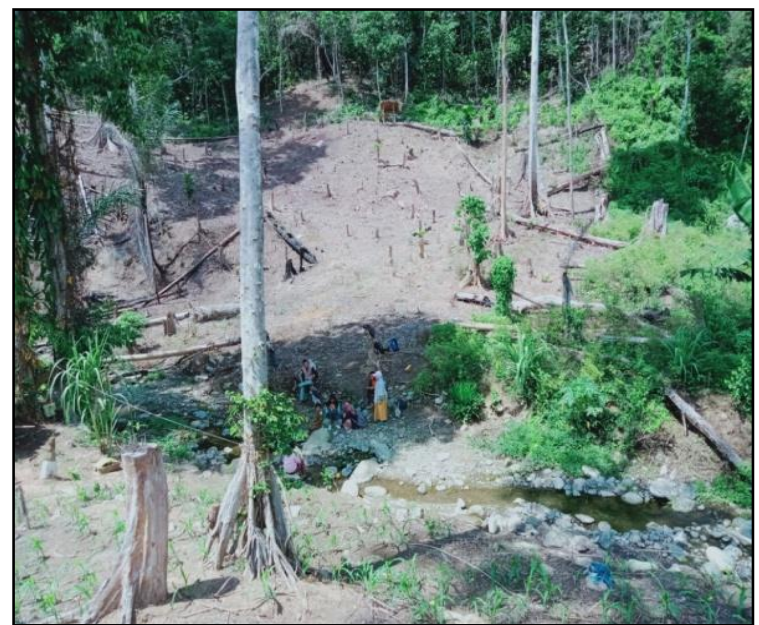

Gambar 2. Pembukaan Lahan Hutan oleh Suku Polahi

Pembukaan lahan dengan cara tersebut sebenarnya telah menjadi perhatian dari instansi pemerintah khususnya dari dinas kehutanan, tetapi sikap Suku Polahi yang susah untuk didekati dan tidak ingin berinteraksi menjadi kendala utama, sehingga pendekatan secara persuasif dari masyarakat lainnya perlu dilakukan. Berdasarkan permasalahan diatas, tim PKM-M Politeknik Gorontalo berinisiatif melakukan pola tanam dengan cara Agroforestri, selain mengenalkan kepada mereka pola tanam yang baik sekaligus untuk menjaga kelestarian Suaka Margasatwa Nantu yang menjadi daerah konservasi. Pola tanam Agroforestri yang diperkenalkan yaitu penanaman jagung sebagai makanan bersamaan dengan penanaman bibit pohon matoa, rambutan dan jambu monyet yang merupakan tanaman lokal di Suaka Margasatwa Nantu.

Manfaat yang diharapkan dari kegiatan ini adalah antara lain adalah memperkenalkan metode hutan pertanian (agroforestri) pada Suku Polahi untuk bisa memenuhi kebutuhan dan kesejahteraan hidupnya secara mandiri. Selain itu, kegiatan pengabdian masyarakat ini bertujuan agar masyarakat Suku Polahi dapat menerapkan teknik Agroforestri agar dapat meningkatkan produktivitas pertanian dan selanjutnya dapat mengurangi kerusakan akibat penebangan pohon secara illegal yang akan berdampak pada perusakan di Suaka Margasatwa Nantu.

\section{METODE}

\section{Waktu dan Tempat}

Kegiatan ini dilaksanakan pada bulan Juni sampai Juli 2021 dan berlokasi di Suaka Margasatwa Nantu Boliyohuto Desa Pangahu, Kecamatan Asparaga Kabupaten Gorontalo.

\section{Bahan dan Alat}

Bahan dan alat yang diperlukan antara lain: meteran panjang (ukuran $50 \mathrm{~m}$ ) tali berukuran panjang $100 \mathrm{~m}$ dan $20 \mathrm{~m}$ atau $20 \mathrm{~m}$ dan $5 \mathrm{~m}$, tongkat kayu sepanjang 2,5 $\mathrm{m}$ dan 1,3 $\mathrm{m}$, parang, cangkul, linggis dan blangko pengamatan.

\section{Sosialisasi Kegiatan}

Sosialisasi perlu dilakukan agar Suku Polahi mengetahui maksud dan tujuan dari kegiatan yang akan dilakukan. Sosialisasi ini dilakukan diawal pertemuan dengan melakukan pendekatan secara persuasif dikarenakan Suku Polahi sulit untuk diajak berkomunikasi. Sosialisasi menjadi faktor penting agar kegiatan yang ingin dilakukan disetujui dan juga bisa berjalan dengan lancar selama kegiatan berlangsung. 


\section{Survey Lokasi}

Survey lokasi kegiatan bertujuan untuk mengetahui gambaran umum kondisi lokasi pelaksanaan kegiatan. Kegiatan survei ini dilakukan dengan melaksanakan kunjungan langsung, pengumpulan data sekunder dan berdiskusi dengan Suku Polahi.

\section{Pengukuran Lahan}

Pengukuran lahan dilakukan sebagai berikut:

1. Membuat tanda dari patok kayu (sebagai titik ikat) kemudian merekam posisi titik ikat menggunakan GPS

2. Mengikat tali raffia sepanjang $40 \mathrm{~m}$ dan ditarik ke arah utara. Selanjutnya mengikat tali lain sepanjang $3 \mathrm{~m}$ ke arah timur. Lanjutkan pemasangan patok di 3 sudut yang lain dan mengikat tali yang lain hingga diperoleh plot pengukuran sebesar $40 \mathrm{~m} \times 5 \mathrm{~m}=200 \mathrm{~m}^{2}$ (disebut sub plot).

3. Mencatat dan membuat sketsa plot permanen yang telah dibuat dari titik ikat dengan keterangan arah mata angin yaitu $125 \mathrm{~m}$ kearah utara dan $20 \mathrm{~m}$ kearah timur dari titik ikat

4. Membuat SUB PLOT lebih dari satu dikarenakan kondisi lahan yang berlereng. Pembuatan satu SUB PLOT di setiap bagian lereng (atas, tengah dan lereng bawah).

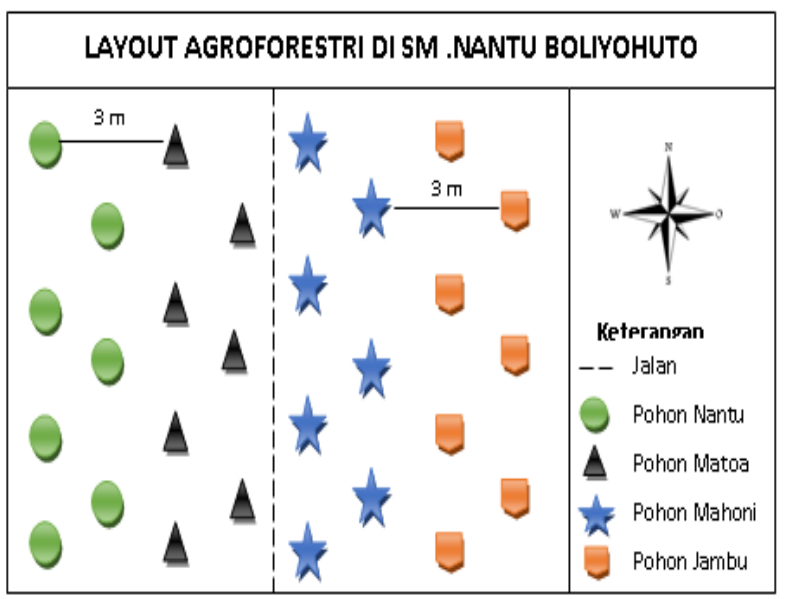

Gambar 3. Rancangan Lay Out Lahan Agroforestri

\section{Penanaman Bibit Pohon}

Penanaman bibit pohon dilakukan dengan sistem Agroforestri yaitu menanam dua buah tanaman pada satu lahan. Penanaman bibit dilakukan dengan membagi dua lahan kemudian menanam secara berdampingan bibit pohon kayu dengan bibit pohon buah. Pada lahan sisi kiri ditanami bibit pohon Nantu dengan Pohon Matoa sedangkan pada sisi kanan ditanami bibit pohon Mahoni dan bibit pohon Jambu. Bibit yang digunakan untuk pohon buah-buahan yang telah berumur 2 bulan sedangkan pada pohon kayukayuan yang telah berumur 3-4 bulan (Gambar 3).

\section{HASIL PEMBAHASAN}

Wawancara dan Sosialisasi

Pengetahuan Tentang Suaka Margasatwa Nantu

Suaka Margasatwa Nantu memilki luas 51.507,33 Ha dan merupakan tempat bagi flora dan fauna yang dilindungi. Kawasan Nantu menjadi tempat tinggal Suku Polahi dari dulu karena itu pengetahuan tentang Suaka Margasatwa Nantu perlu untuk diketahui. Pengetahuan ini seputar tentang keberadaan hewan dilindungi Anoa, Tarsius dan beberapa hewan jenis spesies burung tetapi Suku Polahi tidak mengetahui bahwa Suaka Margasatwa Nantu adalah kawasan konservasi dan dilindungi. Hal ini dikarenakan ketidakinginan Suku Polahi untuk bertemu dengan orang baru dan kesulitan komunikasi, sehingga setiap kali pihak Dinas Kehutanan ingin memberikan sosialisasi selalu tidak tersampaikan dengan baik.

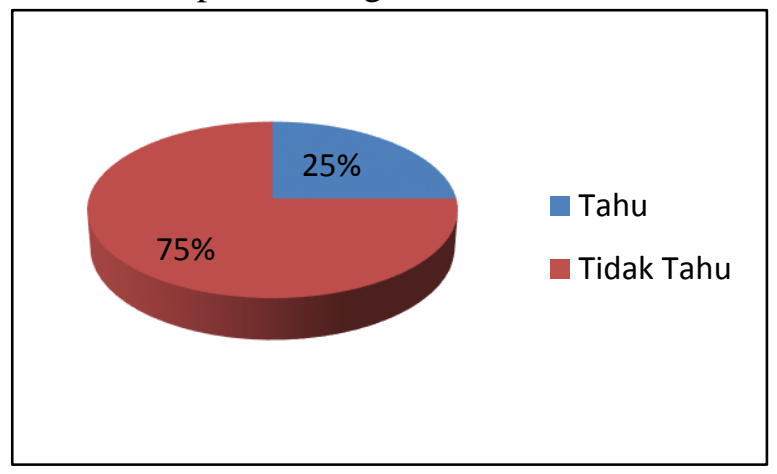

Gambar 4. Respon Suku Polahi Terhadap Status Suaka Margasatwa Nantu

Pengetahuan Tentang Larangan Penebangan Pohon

Pengetahuan tentang larangan penebangan pohon ini bertujuan untuk mengetahui pengetahuan Suhu Polahi tentang pelarangan tersebut. Dari hasil wawancara memperlihatkan bahwa 62\% Suku Polahi mengetahui tentang pelarangan tersebut sedangkan $38 \%$ tidak mengetahui. Walaupun Suku Polahi mengetahui tentang pelarangan tersebut tetapi masih sering mereka lakukan dikarenakan kebutuhan untuk membangun rumah dan juga untuk menanam jagung. Selain menebang pohon Suku Polahi juga melakukan perburuan liar terhadap hewan yang dilindungi, hewan-hewan ini biasanya mereka 
makan atau mereka jual

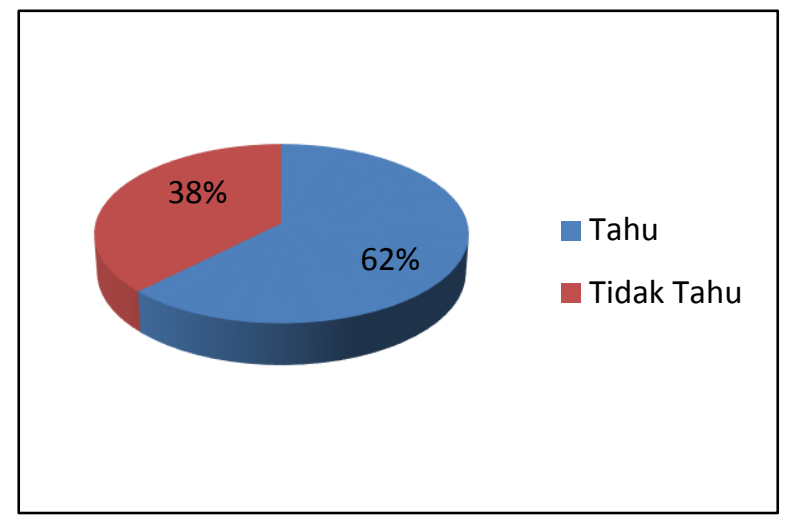

Gambar 5. Respon Suku Polahi Terhadap Penebangan Pohon

\section{Pengetahuan Tentang Erosi dan Longsor}

Erosi dan longsor menjadi faktor penentu apabila terjadi kesalahan dalam penggunaan suatu lahan. Pengetahuan Suku Polahi tentang erosi dan longsor sebagian besar tidak mengetahui hanya ayah dan anak lelaki pertama yang mengetahui. Hasil wawancara memperlihatkan bahwa Suku Polahi hanya mengetahui tentang longsor dan mereka menyebutnya dengan tanah yang jatuh. Suku Polahi beberapa kali berpindah tempat tinggal diakibatnya tanahnya mengalami erosi tetapi Suku Polahi tidak tahu bagaimana cara untuk mengurangi dampak erosi.

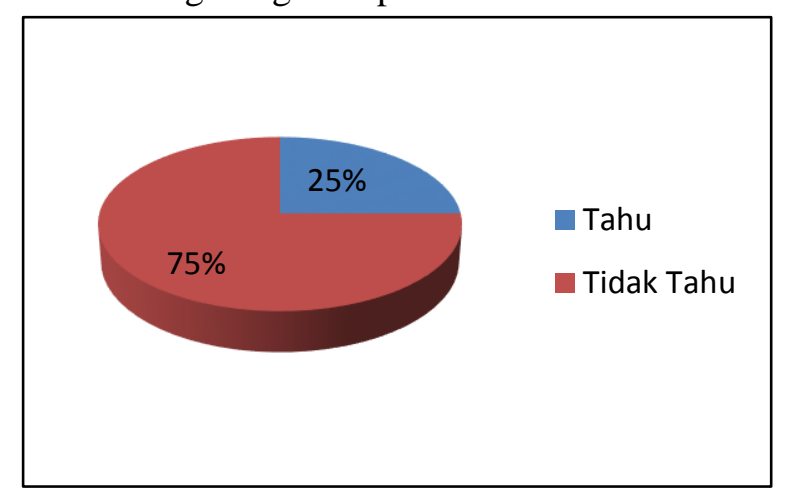

Gambar 6. Diagram Respon Suku Polahi Terhadap Erosi dan Longsor

\section{Pengetahuan Tentang Agroforestri}

Pengetahuan Suku Polahi tentang Agroforestri sama sekali tidak ada, ini dikarenakan Suku Polahi biasanya menanam hanya dengan cara monokultur dan dilakukan pada tanaman jagung saja sedangkan tanaman tahunan tidak pernah ditanam oleh Suku Polahi.
Kesediaan untuk Menjaga dan Merawat Bibit Pohon

Kesediaan Suku Polahi untuk merawat dan menjaga bibit pohon yang telah ditanami menjadi tujuan utama kegiatan ini. Hal ini dikarenakan kegiatan ini akan terus berlangsung dan berjalan dengan baik apabila Suku Polahi memilki kemauan untuk merawat bibit pohon yang telah ditanam. Kesediaan Suku Polahi untuk melakukan penanaman di lahan lainnya termasuk tujuan kedua kegiatan ini, hal ini sebagai upaya untuk mengurangi erosi dan juga agar Suku Polahi yang telah diberikan pelatihan akan memberitahukan kepada anggota Suku Polahi lainnya yang ada di dalam hutan untuk melakukan Agroforestri.

\section{Penanaman Bibit Pohon}

Penaman bibit dilakukan pada pertemuan ketiga dengan Suku Polahi. Penanaman bibit dilakukan berdasarkan kesepakatan yang telah dilakukan sebelumnya pada saat melakukan sosialisasi. Dari hasil pertemuan disepakati bibit pohon yang ditanam adalah bibit pohon Matoa, Mahoni, Jambu Mete dan bibit pohon Nantu.

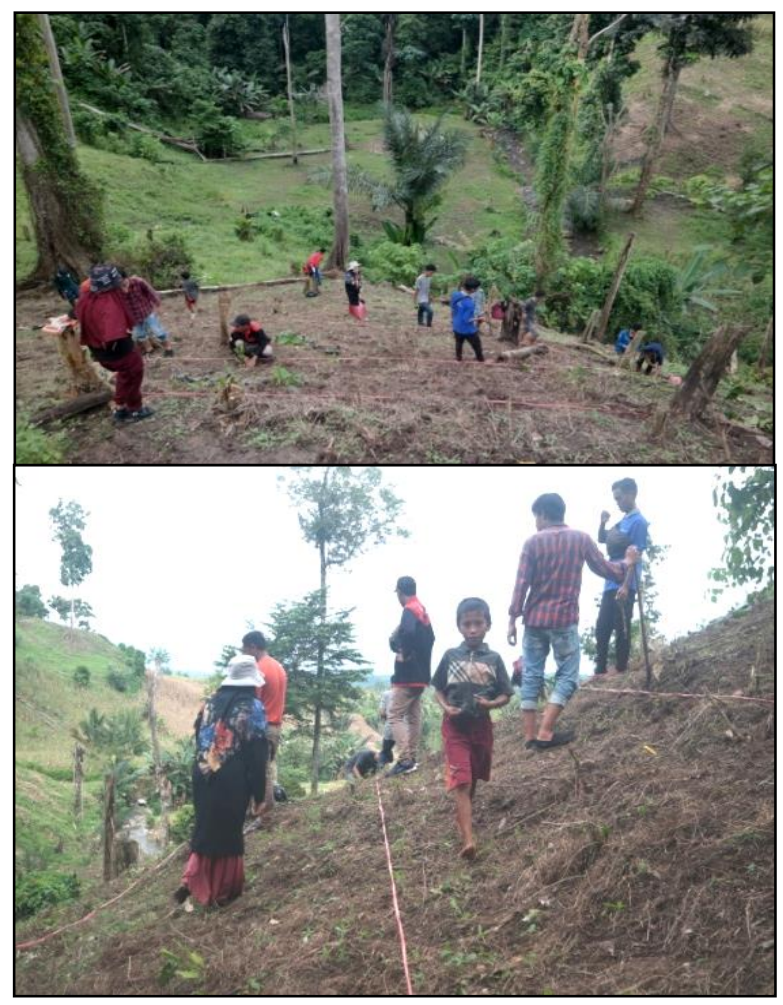

Gambar 7. Kegiatan Pelaksanaan Penanaman Pohon Metode Agroforestri

Agroforestri ini dilakukan dengan cara sederhana yaitu menanam lebih dari satu jenis 
tanaman kayu dalam satu lahan (Aryadi et al., 2013). Penanaman Agroforestri dilakukan dengan menanam bibit pohon Nantu, Matoa, Mahoni dan Jambu Mete dengan umur bibit 3-4 bulan. Penanaman dilakukan dengan membagi empat lahan dan diberikan kode T1 sampai T4. Penanaman dilakukan secara selang seling antara tanaman kayu dengan tanaman buah. Pada lokasi T1 ditanami bibit pohon Nantu yang merupakan tanaman kayu sedangkan lokasi T2 ditanami bibit pohon Matoa yang merupakan tanaman buah. Pada lokasi T3 berdampingan dengan lokasi T4 yang ditanami bibit pohon Mahoni yang merupakan tanaman kayu dan bibit Pohon Jambu Mete yang merupakan tanaman buah.

Tabel 1. Manfaat Bibit Pohon yang Ditanam

\begin{tabular}{|cc|cr|c|}
\hline No & Tanaman & Manfaat & $\begin{array}{c}\text { Fungsi } \\
\text { Ekologis }\end{array}$ & $\begin{array}{c}\text { Umur } \\
\text { Dipanen }\end{array}$ \\
\hline T1 & $\begin{array}{l}\text { Pohon } \\
\text { Nantu }\end{array}$ & Kayu & $\begin{array}{r}\text { Konservasi } \\
\text { tanah dan } \\
\text { air }\end{array}$ & - \\
\hline T2 & $\begin{array}{l}\text { Pohon } \\
\text { Matoa }\end{array}$ & Buah & $\begin{array}{r}\text { Konservasi } \\
\text { tanah dan } \\
\text { air }\end{array}$ & $\begin{array}{l}6 \text { tahun, lalu } \\
\text { tiap 2 bulan }\end{array}$ \\
\hline T3 & $\begin{array}{l}\text { Pohon } \\
\text { Mahoni }\end{array}$ & Kayu & $\begin{array}{r}\text { Konservasi } \\
\text { tanah dan } \\
\text { air }\end{array}$ & - \\
\hline T4 & $\begin{array}{l}\text { Pohon } \\
\text { Jambu } \\
\text { Mete }\end{array}$ & Buah & $\begin{array}{l}\text { Konservasi } \\
\text { tanah dan } \\
\text { air }\end{array}$ & $\begin{array}{l}4 \text { tahun, lalu } \\
\text { tiap 2 bulan }\end{array}$ \\
\hline
\end{tabular}

\section{KESIMPULAN}

Program kegiatan yang telah dilaksanakan berupa sosialisasi, pelatihan, penanaman dan pemberian alat pertanian mendapatkan respon yang baik dari Suku Polahi. Kegiatan ini juga menjadi awal terbuka Suku Polahi untuk bisa bersosialisasi dengan orang baru dan juga membantu Tim dari BKSDA yang sulit untuk menjalin komunikasi dengan Suku Polahi. Setelah dilakukan pelatihan ini Suku Polahi mengetahui tentang agroforestri dan mengharapkan bahwa Suku Polahi yang telah bergabung dalam kegiatan ini kemudian berkomitmen untuk tetap menjaga kelestarian Suaka Margasatwa Nantu. Sampai saat ini keberadaan Suku Polahi yang bisa teridentifikasi tidak lebih dari 5 Kepala Keluarga karena itu dengan berjalannya kegiatan ini sangat diharapkan bisa membuka komunikasi dengan Suku Polahi lainnya dan bisa melakukan kegiatan edukatif lainnya.
Pelaksanaan kegiatan ini membutuhkan koordinasi yang sangat matang, dimulai dengan perizinan memasuki kawasan hutan, perizinan penanaman bibit hingga koordinasi untuk bisa berkomunikasi dengan Suku Polahi. Koordinasi lebih awal sangat efisien untuk mempermudah terlaksananya kegiatan. Penguasaan pemahaman kegiatan juga harus dimatangkan diawal kegiatan agar saat dilapangan kegiatan bisa berjalan tepat dengan waktu yang telah ditentukan. Harapan kegiatan berikutnya yaitu melakukan kegiatan agroforestri dengan masyarakat yang berada di sekitar wilayah Suaka Margasatwa Nantu.

\section{UCAPAN TERIMA KASIH}

Tim Pengabdian Kepada Masyarakat mengucapkan terima kasih kepada Kementerian Pendidikan, Kebudayaan, Riset dan Teknologi atas pembiayaan kegiatan ini. Tim Lapangan dari BKSDA Wilayah II Gorontalo yang selama proses di lapangan banyak membantu dan untuk semua mahasiswa Politeknik Gorontalo yang telah terlibat dalam kegiatan ini.

\section{DAFTAR PUSTAKA}

Aryadi, M., Agustina, A., Prihatiningtyas, E. (2013). Evaluasi Komponen Penyusun Sistem Agroforestri Di Desa Sungai Alang, Kecamatan Karang Intan, Kabupaten Banjar, Kalimantan Selatan. Prosiding Seminar Nasional Agroforestri, Hal 49-54.

[BKSDA] Balai Konservasi Sumber Daya Alam. (2020) Laporan Tahunan Suaka Margasatwa Nantu. Desember 2020. Gorontalo

Pomalingo, S. (2015) Polahi: Komunitas Pedalaman Suku Gorontalo. Jurnal Dinamika Sosial dan Budaya. Vol.1.(1), Juli 2015:53-62

Rahim, S. (2015) Komunitas Perilaku Lingkungan Perempuan Polahi di Kawasan Hutan Lokasi Desa Bihe Kecamatan Asparaga Kabupaten Gorontalo. Jurnal MUSAWARA. Vol.7 (1), Juni 2015: 121-158

Wikipedia. (2021) Suaka Margasatwa Nantu Provinsi Gorontalo. URL: https://id.wikipedia.org/wiki/Suaka_Margasat wa_Nantu. Diakses tanggal 3 Juni 2021 